Tropical Journal of Pharmaceutical Research October 2016; 15 (10): 2209-2217

ISSN: $1596-5996$ (print); 1596-9827 (electronic)

(C) Pharmacotherapy Group, Faculty of Pharmacy, University of Benin, Benin City, 300001 Nigeria.

All rights reserved.

Available online at http://www.tjpr.org

Original Research Article

http://dx.doi.org/10.4314/tjpr.v15i10.20

\title{
Enhanced spectrofluorimetric determination of the multitargeted tyrosine kinase inhibitor, crizotinib, in human plasma via micelle-mediated approach
}

\author{
Hany W Darwish ${ }^{1,2 *}$, Ahmed H Bakheit ${ }^{1}$, Ibrahim A Darwish ${ }^{1}$ \\ ${ }^{1}$ Department of Pharmaceutical Chemistry, College of Pharmacy, King Saud University, P.O. Box 2457 Riyadh, 11451, \\ Kingdom of Saudi Arabia, ${ }^{2}$ Analytical Chemistry Department, Faculty of Pharmacy, Cairo University, Kasr El-Aini St, Cairo \\ 11562, Egypt
}

*For correspondence: Email: hdarwish75@yahoo.com

Revised accepted: 2 September 2016

\begin{abstract}
Purpose: To quantify the multi-targeted tyrosine kinase inhibitor, crizotinib, in human plasma and bulk powder by highly sensitive micellar enhanced spectrofluorimetric procedure.

Method: The developed procedure was based on measuring the fluorescence intensity of crizotinib (CRZ) in sodium dodecyl sulphate (SDS) micellar system at $404 \mathrm{~nm}$ after excitation at $271 \mathrm{~nm}$. Validation of the developed procedure was carried out following ICH (International Council for Harmonization) guidelines.

Results: Maximum fluorescence intensity (FI) was attained by addition of $0.2 \mathrm{~mL} S D S$ and $0.2 \mathrm{~mL} \mathrm{HCl}$ $(1 N)$ to $C R Z$ aliquots and then dilution with distilled water. There was a linear relationship between the $\mathrm{FI}$ of CRZ and its concentration over the range, $5-400 \mathrm{ng} / \mathrm{mL}$, with limit of detection and of quantification of 1.857 and $5.628 \mathrm{ng} / \mathrm{mL}$ respectively. The developed procedure was successfully applied to assay CRZ in pure powder form and spiked human plasma with mean recovery of $100.68 \pm$ 0.37 and $99.98 \pm 0.20 \%$, respectively.

Conclusion: The developed procedure is simple and sensitive, and can be applied to routine analysis of CRZ in pure powder form as well as in clinical laboratories for the determination of CRZ in plasma.
\end{abstract}

Keywords: Crizotinib, Spectrofluorimetry, Micelle, Human plasma, Sodium dodecyl sulphate

\begin{abstract}
Tropical Journal of Pharmaceutical Research is indexed by Science Citation Index (SciSearch), Scopus, International Pharmaceutical Abstract, Chemical Abstracts, Embase, Index Copernicus, EBSCO, African Index Medicus, JournalSeek, Journal Citation Reports/Science Edition, Directory of Open Access Journals (DOAJ), African Journal Online, Bioline International, Open-J-Gate and Pharmacy Abstracts
\end{abstract}

\section{INTRODUCTION}

Crizotinib (CRZ, Figure 1) is one of the new tyrosine kinase inhibitors (TKIs) which is chemically known as 3-[(1R)-1-(2, 6-dichloro-3fluorophenyl) ethoxy]-5-(1-piperidin-4-ylpyrazol4-yl) pyridine-2-amine. CRZ binds to the ATPbinding pocket of the correspondent kinase in a competitive manner [1-4]. Its targeting kinases include anaplastic lymphoma kinase (ALK), mesenchymal-epithelial transition factor (MET), and other tyrosine kinases.
It is used effectively in patients suffering from non-small cell lung cancer (NSCLC). Food and Drug Administration (FDA) has approved CRZ in 2011 for the management of NSCLC due to its success in two clinical trials [5]. CRZ is available in the market under the name of Xalkoriß capsule and is manufactured by Pfizer, Inc. The absorption of CRZ is not influenced by foodstuff and its maximum plasma concentration attained after $4 \mathrm{~h}$ following administration of one dose. Currently, a binary combination of CRZ and 
dasatinib is under evaluation for treating highgrade glioma (HGG) or diffuse intrinsic pontine glioma (DIPG). The positive results of using this binary combination may involve pharmacokinetic interaction between the two drugs as CRZ is considered an inhibitor of CYP3A. Unfortunately, CRZ pharmacokinetic disposition, in infants suffering from malignant brain tumors, is not known till now. Accordingly, reliable and accurate analytical methodology for CRZ determination is crucial for further pharmacokinetic studies. Literature review revealed that CRZ was assayed in plasma by liquid chromatography coupled with either tandem mass spectrometry [6-9] or fluorescence detection [10]. However, these chromatographic methods suffered from complexity and being expensive. Few spectrophotometric methods have been reported for determination of CRZ in dosage form [11-13]. Thus development of simple and sensitive analytical methodology for CRZ determination in plasma is demanded. Accordingly, in the current study a rapid, sensitive and reliable spectrofluorimetric method was conducted for the assay of CRZ in plasma. The present method involved micellar enhancement of $\mathrm{FI}$ of $\mathrm{CRZ}$ utilizing SDS as a sensing agent. Application of micellar enhancement approach in spectrofluorimetry was applied to assay small molecules by virtue of its high sensitivity [14-16] due to the ability of the formed micelle to decrease the free rotational motions and thus protect the analyte molecules from the radiationless deactivation process [16]. Additionally, this approach represents effective and echo-friendly methodology because there is no application of organic solvents throughout the whole study.

\section{EXPERIMENTAL}

\section{Reagents and materials}

Solvents utilized in this study were of HPLC grade (Merck, Darmstadt, Germany) while chemicals were of analytical grade. Reference powder of CRZ (purity 99.6\%) was procured from Weihua Pharma Co. Ltd (Zhejiang, China). SDS (Sodium dodecyl sulphate; $95 \%$ ) was purchased from Winlab (Pontefract, London, UK) and prepared as $1 \%$ aqueous w/v. Cremophor RH 40 and Cremophor EL were procured from BASF (Ludwigshafen, Germany) and prepared as $1 \% \mathrm{v} / \mathrm{v}$ aqueous solutions. Both $\beta-\mathrm{CD}(\beta-$ cyclodextrin) and CMC (carboxymethylcellulose) were procured from Merck (Darmstadt, Germany) and prepared as $1 \% \mathrm{w} / \mathrm{v}$ aqueous solutions. Tween 20 , tween 80 and tween 85 were procured from Techno Pharmchem Haryana Company (New Delhi, India) and prepared as $1 \% \mathrm{v} / \mathrm{v}$ aqueous solution. Ethanol and methanol were purchased from VWR Prolabo (Fontenay Sous Bois, France) and acetonitrile was purchased from Sigma-Aldrich Chemie GmbH (Schnelldorf, Germany). $0.1 \mathrm{M}$ Phosphate buffer and $0.1 \mathrm{M}$ borate buffer, covering the $\mathrm{pH}$ ranges 2-12 were freshly prepared and ultrapure water was acquired through a Millipore Milli-Q® UF Plus water purifier (MA, USA). Plasma samples were obtained from King Khaled University Hospital (KSU, Riyadh, Saudi Arabia). All patients provided written informed consent, then fasting blood specimens were collected followed by plasma separation and storage at $-70^{\circ} \mathrm{C}$.

\section{Instrumentation}

Normal fluorescence measurements were recorded utilizing Jasco FP-8200 Fluorescence Spectrometer (Jasco Corporation, Japan) fitted with a xenon lamp $(150 \mathrm{~W})$ and standard $10 \mathrm{~mm}$ pathlength quartz cell with bandwidth of $5 \mathrm{~nm}$ for both excitation and emission monochromators. Quinine sulphate solution $\left(0.01 \mu \mathrm{gmL}^{-1}\right)$ was frequently utilized for calibration of Fluorescence Spectrometer. Data acquisition was executed by SpectraManager ${ }^{\circledR}$ software. $\mathrm{pH}$ measurements were done utilizing Hanna pH-Meter (Romania).

\section{Preparation of standard stock and working solutions}

Accurately quantity of CRZ $(25 \mathrm{mg})$ was weighed and transferred into a $25 \mathrm{~mL}$ measuring flask, dissolved in methanol and made up $t$ to mark with same solvent to prepare a stock solution of CRZ (1 mg/mL). CRZ stock solution was diluted afterwards with methanol to prepare working standard solution of $1 \mu \mathrm{g} / \mathrm{mL}$. For fourteen days, these standard solutions were stable when stored in the refrigerator.

\section{Sample preparation and generation of calibration curve}

Calibration samples were prepared by accurately transferring aliquots of CRZ standard solutions to five $\mathrm{mL}$ calibrated flasks followed by addition of $0.2 \mathrm{~mL}$ of SDS and $0.2 \mathrm{~mL}$ of $\mathrm{HCl}(1 \mathrm{~N})$ and completing volume by ultrapure distilled water to yield final concentrations of $5-400 \mathrm{ng} / \mathrm{mL}$. Mixing of the flasks' contents took place followed by recording $\mathrm{FI}$ at $404 \mathrm{~nm}$ after excitation at 271 nm. Calibration curve was generated by plotting $\mathrm{FI}$ of calibration samples versus CRZ concentrations in $\mathrm{ng} / \mathrm{mL}$. Finally, the regression equation was computed and utilized to calculate 
CRZ concentrations in different samples depending on their $\mathrm{FI}$.

\section{Analysis of human plasma samples}

Accurate volume $(20 \mu \mathrm{L})$ of standard solutions of CRZ (correspond to different concentrations of CRZ)) were spiked individually to a one $\mathrm{mL}$ portion of free drug human plasma and mixed well for $1 \mathrm{~min}$ to yield CRZ final concentrations of 150, 200 and $250 \mathrm{ng} / \mathrm{mL}$. Thereafter, addition of $1 \mathrm{~mL}$ of $\mathrm{NaOH}(100 \mathrm{mM})$ /glycine buffer $\mathrm{pH} 12$ and the Eppendorf tube was vortexed for $10 \mathrm{~s}$. Afterwards, $5 \mathrm{~mL}$ of diethyl ether was added Tube was then vortexed once again for $30 \mathrm{~s}$ and then centrifuged at $10,000 \mathrm{rpm}$ for $15 \mathrm{~min}$ for complete phase separation. Accurate volume of the upper organic layer was transferred to glass vials and dried using gentle stream of nitrogen. Ultimately, reconstitution of the residue took place in methanol and general steps of calibration curve generation were followed. Blank plasma samples were treated and prepared in a similar way. FI of CRZ was measured at the emission wavelength (404 $\mathrm{nm}$ ) after excitation at $271 \mathrm{~nm}$, then concentrations of CRZ were calculated from calibration graph of the drug constructed in plasma matrix.

\section{RESULTS}

In the current study, micellar enhanced spectrofluorimetric method was developed for assaying CRZ (Figure 1) in plasma. This approach is characterized by the simplicity and sensitivity of spectroscopic technique that enables one to quantify CRZ in plasma. Hence, this approach is considered a typical alternative to the reported chromatographic methods for quantitation of $\mathrm{CRZ}$ in plasma. Different parameters affecting $\mathrm{FI}$ of CRZ were studied and optimized using one factor at a time in the optimization studies. Fluorescence spectra of CRZ in water and SDS micellar medium are displayed in Figure 2.<smiles>C[C@@H](Oc1cc(-c2cnn(C3CCNCC3)c2)cnc1N)c1c(Cl)ccc(F)c1Cl</smiles>

Figure 1: Chemical structure of Crizotinib (CRZ)

\section{Experimental conditions optimization}

Several experiments were performed to optimize the different parameters that affect the FI of CRZ. First of all, different types of organized media were added to aliquots of CRZ solution to inspect their effect on CRZ response. These organized media included SDS as an example for anionic surface active agent,
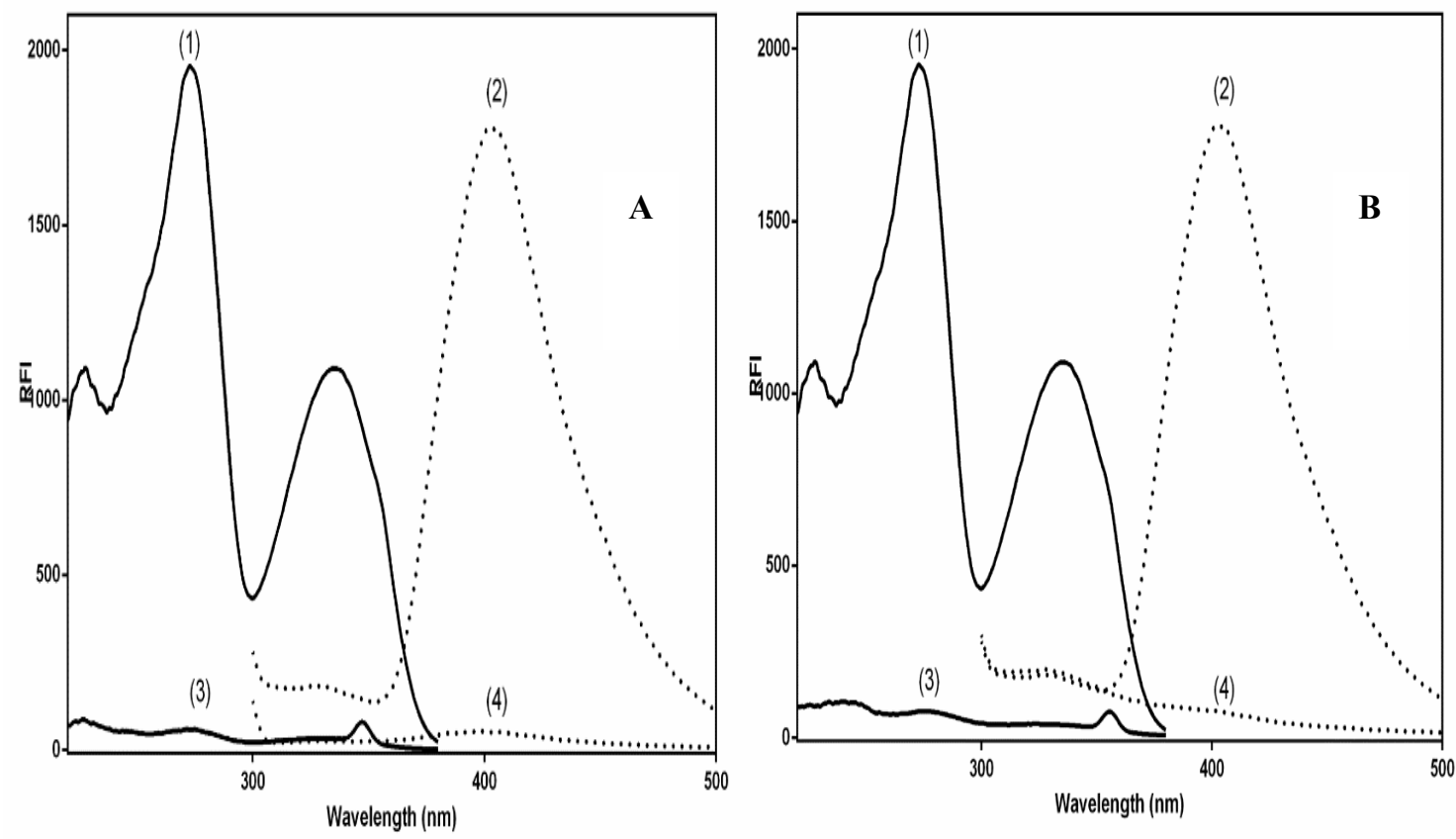

Figure 2: Excitation (1) and emission (2) spectra of CRZ (100 ng/mL) in SDS (1\%, w/v); (A) excitation (3) and emission (4) spectra of CRZ (100 ng/mL) in water; (B) excitation (3) and emission (4) spectra of SDS (1 \%, w/v) in water 
tween 20, 80 and 85, Cremophor El, Cremophor $\mathrm{RH} 40$ as examples for nonionic surface active agents in addition to carboxymethyl cellulose (CMC), and macromolecules such as $\beta$ cyclodextrin. Accordingly, $0.5 \mathrm{~mL}$ of various organized media was added to CRZ standard solution. The best result was acquired by addition of SDS as seen in Figure 3.

Different volumes of $1 \% \mathrm{w} / \mathrm{v}$ aqueous solution of SDS were added to CRZ standard solution. Figure. 4 anticipated that maximum FI of CRZ was attained by addition of $0.2 \mathrm{~mL}$ SDS. Any further increase in volume of SDS did not affect the $\mathrm{FI}$ of the cited drug and as a result, $0.2 \mathrm{~mL} 1$ $\% \mathrm{w} / \mathrm{v}$ SDS solution was chosen throughout the study.
The effect of $\mathrm{pH}$ was also studied by adding different buffers to $\mathrm{CRZ}$ solution. The whole $\mathrm{pH}$ range was covered utilizing $\mathrm{HCl}, 0.1 \mathrm{M}$ borate buffer and $0.1 \mathrm{M}$ borate buffer individually. The data showed that maximum $\mathrm{FI}$ was recorded utilizing $1 \mathrm{~N} \mathrm{HCl}(\mathrm{pH}<1)$ and on increasing $\mathrm{pH}$, the $\mathrm{FI}$ decreased markedly as anticipated in Figure 5.

From these data, it was believed that at low $\mathrm{pH}$, CRZ is in the cationic form and thus interact favorably with the SDS negative sulphonyl (OSO3 ${ }^{-}$) group. Calculations carried out by Chemicalize [17] supported this thought which pointed out that the $\mathrm{CRZ}$ acquired maximum positive charge at low $\mathrm{pH}$ which in turn reflects that the cationic form of $C R Z$ is the dominant form. The suggested interaction between CRZ and SDS is displayed in Scheme 1.

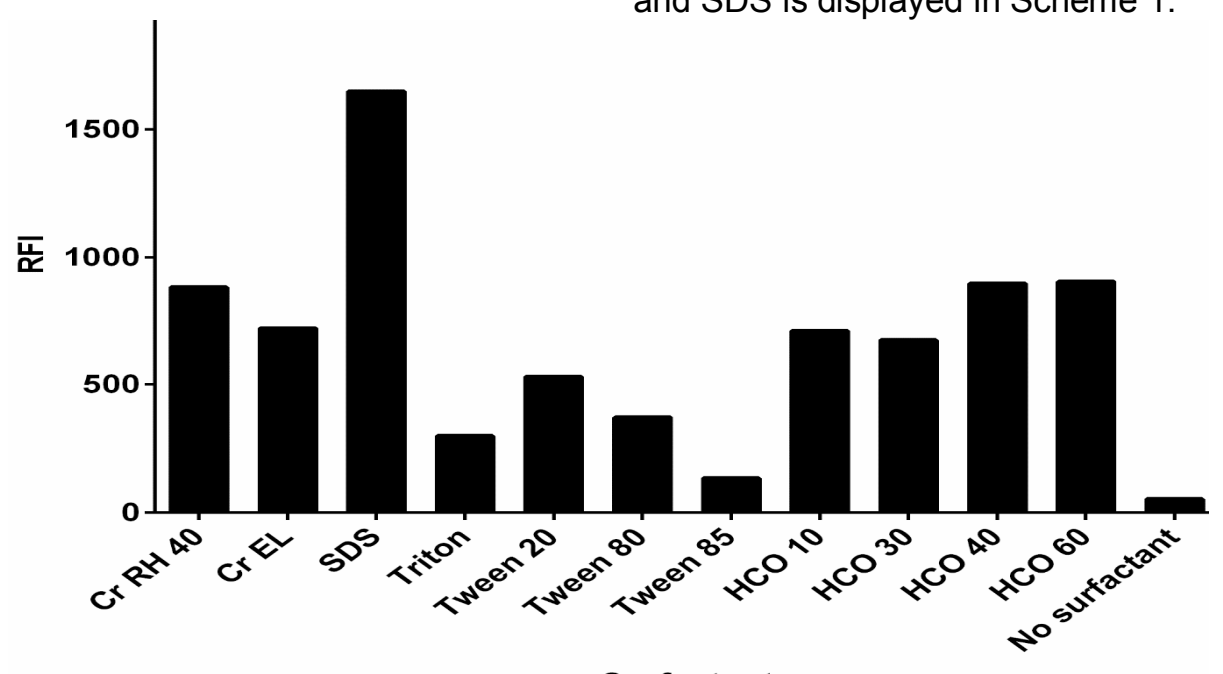

Surfactant

Figure 3: Effect of the type of organized media $(0.2 \mathrm{~mL}, 1 \% \mathrm{w} / \mathrm{v}$ solution of each) on fluorescence intensity of CRZ (100 ng/mL)

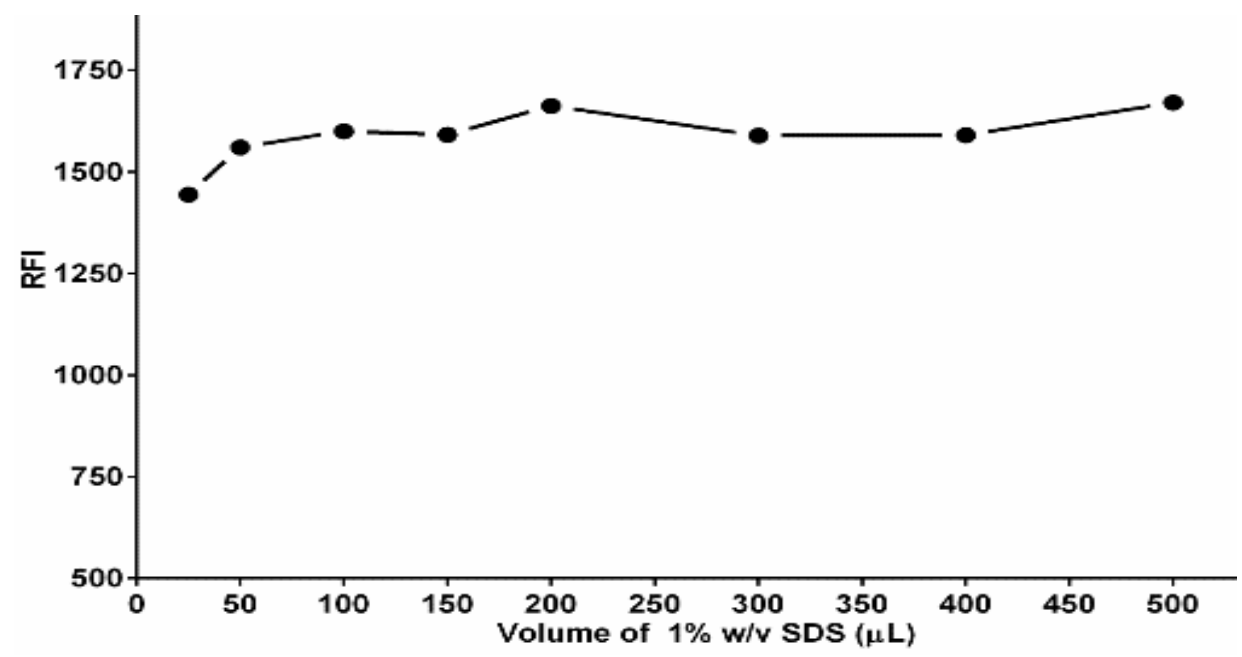

Figure 4: Effect of Sodium dodecyl sulfate (SDS) volume $(1 \% \mathrm{w} / \mathrm{v})$ on fluorescence intensity of CRZB (100 $\mathrm{ngmL}^{-1}$ ) 


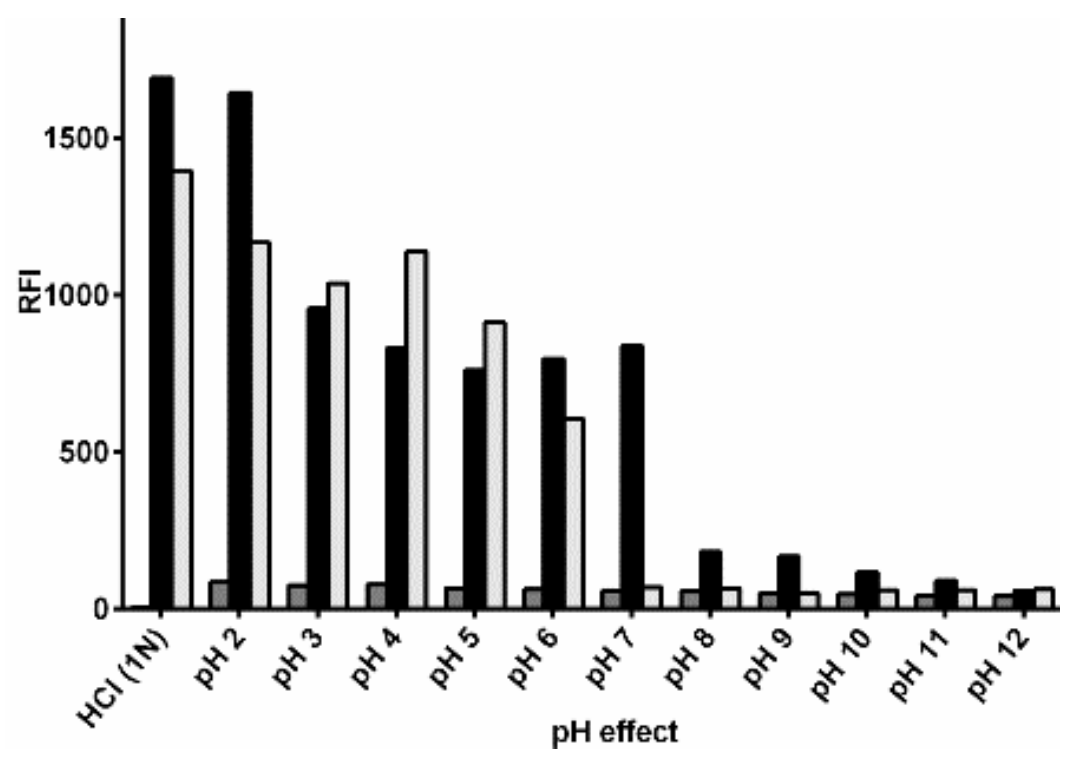

Figure 5: Effect of $\mathrm{pH}$ on the $\mathrm{FI}$ of $100 \mathrm{ng} / \mathrm{mL} \mathrm{CRZ} \mathrm{in} 0.2 \mathrm{~mL} 1 \%$, w/v Sodium dodecyl sulfate (SDS) solution in water (black column CRZ with surfactant, white column CRZ without surfactant and gray column surfactant only)

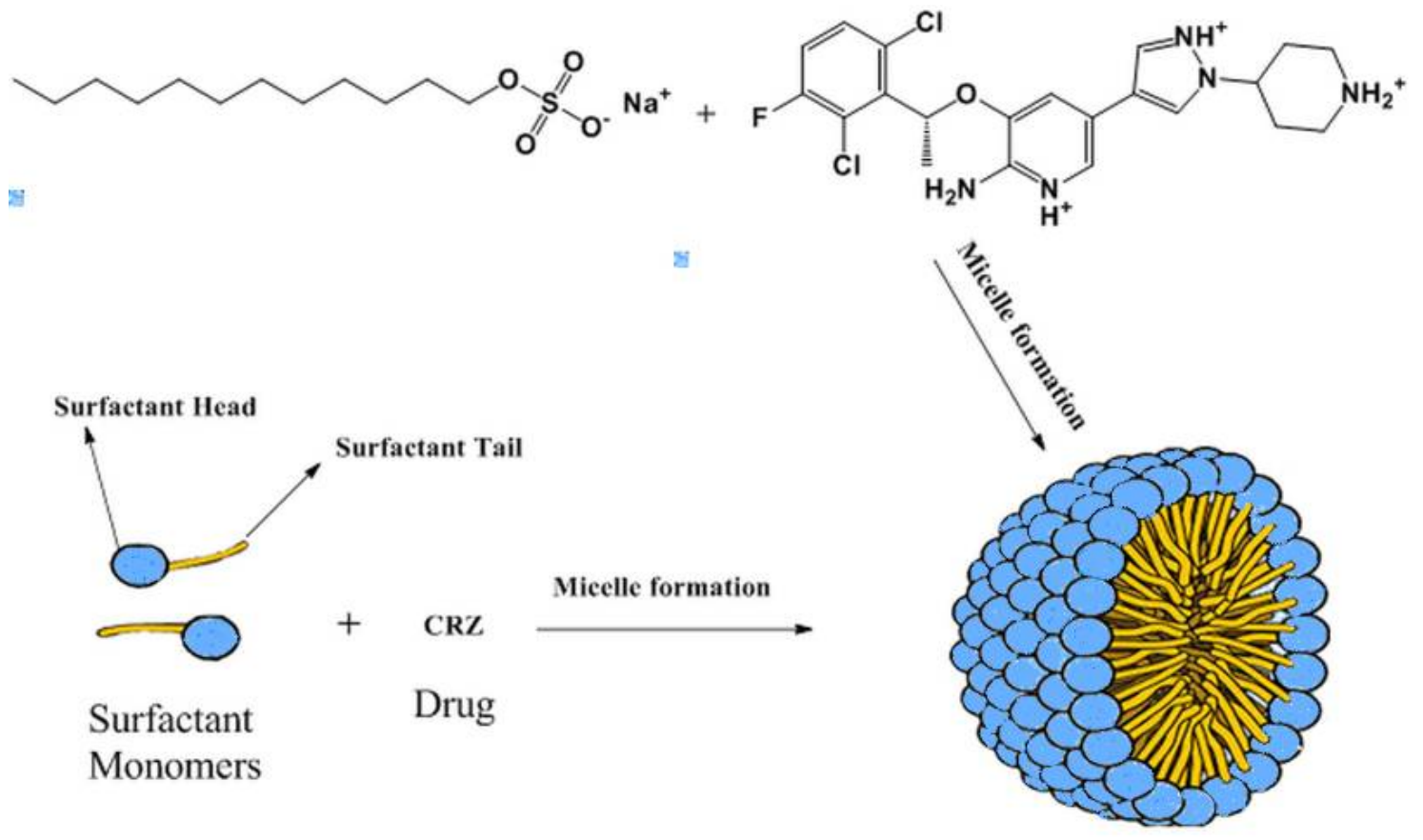

Micelle

Scheme 1: Suggested mechanism for CRZ-SDS micelle formation

Ultimately, the factor of dilution was taken into account by adding various solvents such as; water, methanol, ethanol and acetonitrile. The response was almost equal utilizing different solvents as displayed in Figure 6. Accordingly, water was used for dilution to increase the greenness of the proposed method. The stability of FI of CRZ was also studied versus time and it was revealed that the fluorescence property of CRZ in SDS micellar medium was developed immediately and remained stable for at least 60 $\min$.

\section{Validation results}

\section{Linearity and sensitivity}

Method linearity was confirmed by generation of the calibration curve through plotting the $\mathrm{FI}$ of CRZ, as y-axis, against the corresponding amounts of $C R Z$ in $n g / m L$, as $x$-axis. Linearity of CRZ in organized medium (SDS) ranged between 5 and $400 \mathrm{ng} / \mathrm{mL}$ as depicted in Table 1. Statistical results [18] were also displayed in Table 1 showing minimal values of; standard 
deviation of slope, standard deviation of intercept and standard deviation of residuals in addition to low values of \% RSD and \% error for triplicate samples. Additionally, determination coefficient value was almost equal unity. These abovementioned values confirmed the linearity of the adopted method. Additionally, method linearity was checked by plotting ratio of fluorescence intensity- CRZ concentration (as y-axis) against log CRZ concentration (as $\mathrm{x}$-axis) as shown in Figure 7 [19].

For assessment of method sensitivity, limits of quantification (LOQ) and detection (LOD) were found to be 5.628 and 1.857 respectively. LOQ and LOD were calculated utilizing the following equations:
$L O Q=10(\rho / n)$

$\operatorname{LOD}=3.3(\rho / n)$

where, $\rho$ and $n$ are the standard deviation of intercept and slope of regression line slope, respectively. The results are displayed in Table 1.

Literature [20] revealed that peak plasma concentration of $\mathrm{CRZ}$ is $274 \mathrm{ng} / \mathrm{mL}$, which is quite higher than the LOQ of our adopted method, and therefore, determination of CRZ in human plasma samples can be proceeded reliably.

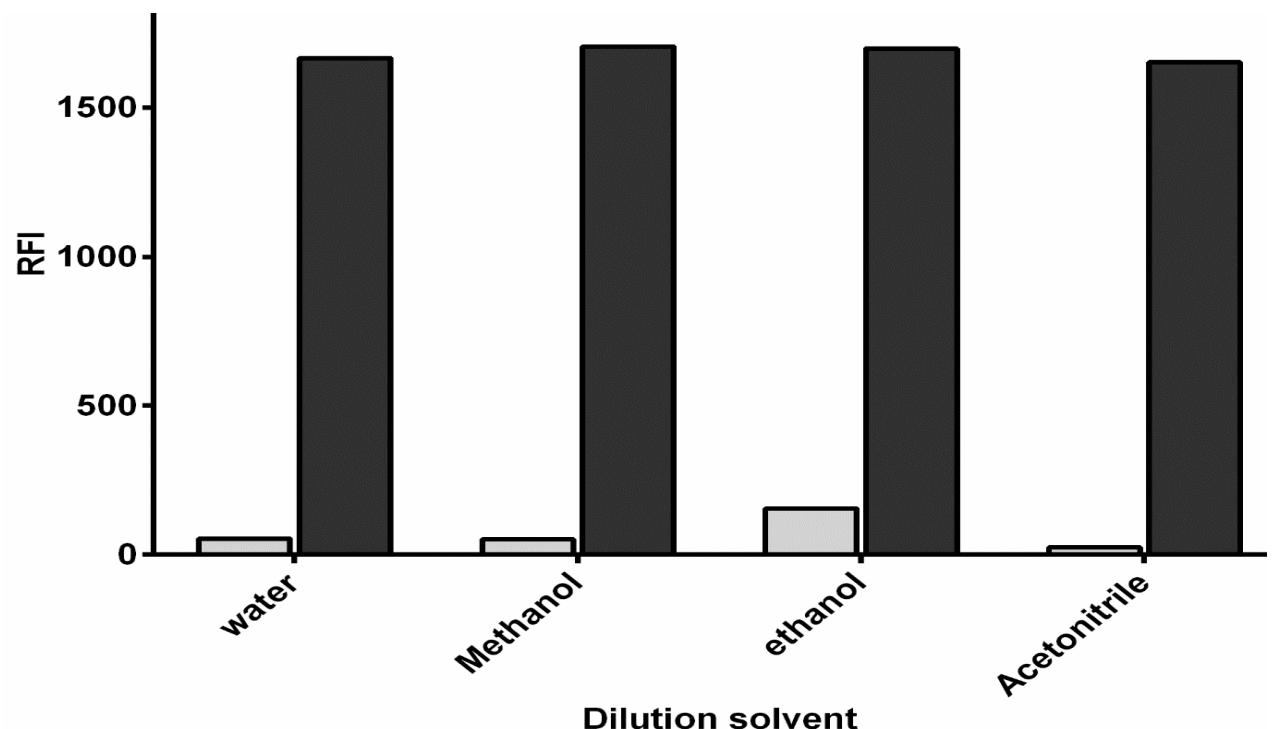

Figure 6: Effect of the diluting solvent on fluorescence intensity of CRZ (100 ng/mL); white column without surfactant and black column with surfactant

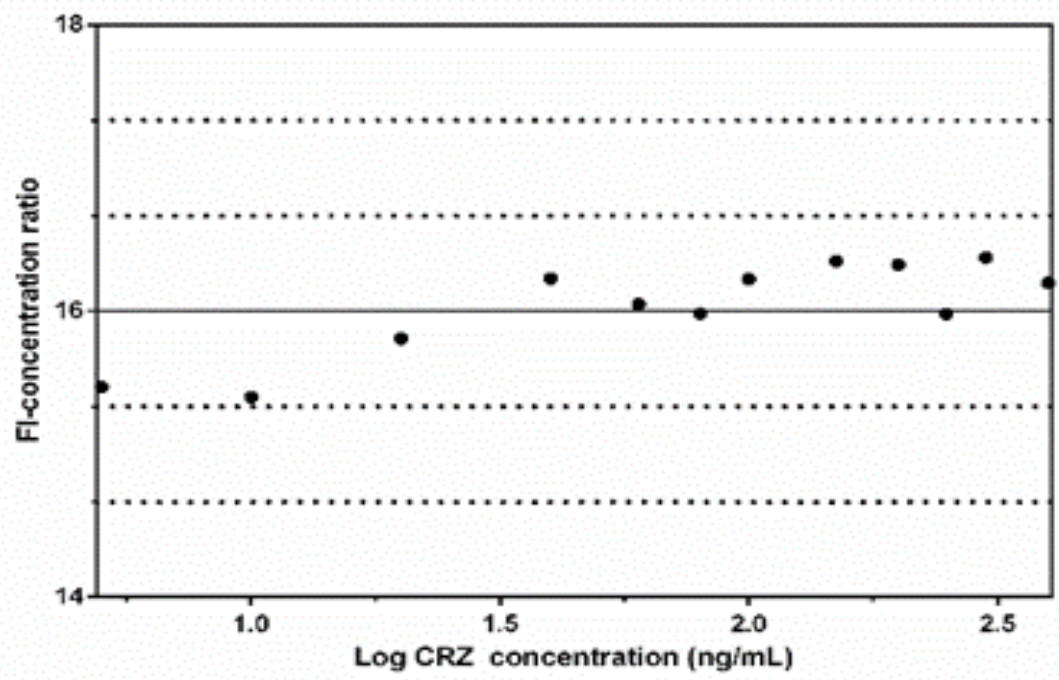

Figure 7: Validation of linearity of the analytical method of CRZ 
Table 1: Analytical performance data for the spectrofluorimetric determination of CRZ

\begin{tabular}{|c|c|}
\hline Parameter & CZB \\
\hline Wavelength $\left[\lambda_{\mathrm{ex}} \lambda_{\mathrm{em}}\right](\mathrm{nm})$ & $271 / 404$ \\
\hline Linearity range $(\mathrm{ng} / \mathrm{mL})$ & $5-400$ \\
\hline Intercept (a) & -5.810 \\
\hline Slope (b) & 16.24 \\
\hline Correlation coefficient $(r)$ & 0.9999 \\
\hline S.D. of residuals $\left(S_{y / x}\right)$ & 36.90 \\
\hline S.D. of intercept $\left(S_{a}\right)$ & 9.140 \\
\hline S.D. of slope $\left(S_{b}\right)$ & 0.0502 \\
\hline$\% \mathrm{RSD}^{\mathrm{a}}$ & 0.355 \\
\hline$\%$ Error $^{\mathrm{D}}$ & -0.699 \\
\hline $\operatorname{LOD}(\mathrm{ng} / \mathrm{mL})^{\mathrm{c}}$ & 1.857 \\
\hline $\operatorname{LOQ}(\mathrm{ng} / \mathrm{mL})^{\mathrm{d}}$ & 5.628 \\
\hline $\begin{array}{l}\text { \% Relative standard de } \\
\text { error for three replicate sa } \\
\text { limit of quantitation }\end{array}$ & $\begin{array}{l}=3) ;{ }^{b} \% \\
\text { mit of det }\end{array}$ \\
\hline
\end{tabular}

\section{Accuracy and precision}

Accuracy, intra- and inter-day precisions were computed following the guidelines stated by International Conference on Harmonization (ICH) for validation of analytical procedures [21]. Results of accuracy and precisions were displayed in Tables 2 and 3. For calculation of intra- and inter-day precisions, triplicate samples corresponding to four different concentrations of CRZ were assayed in one day and in three different successive days respectively.
Precisions were labelled in terms of percentages recovery. Average percentage recovery was around $100 \%$ and RSD values were low (Table 3). Accuracy was described in terms of \% RSD and standard error of mean (SEM). The small values of both \% RSD and SEM were indicative for the accuracy of the current spectrofluorimetric method.

\section{Robustness}

Table 4 summarized the results of the method robustness by evaluating the liability of determinations to deliberate changes of the experimental conditions. It was found that small changes that possibly occur during the experimental runs will have no significant effect on the fluorescence intensity of the cited drug. The temperature values were kept constant by the aid of thermostatic water bath.

\section{Selectivity}

Method selectivity was evaluated by assaying CRZ in plasma (as an example for biological matrix). Table 5 displayed the results for analysis of plasma samples, indicating the selectivity of the suggested procedure as there was no observed interference from endogenous plasma components.

Table 2: Accuracy of the suggested spectrofluorimetric method for assaying CRZ

\begin{tabular}{lcccccc}
\hline Day & $\begin{array}{c}\text { Actual } \\
\text { Conc. } \\
\text { (ng/mL) }\end{array}$ & $\begin{array}{c}\text { Mean } \\
\text { Conc. } \\
\text { (ng/mL) }\end{array}$ & $\mathbf{\pm ~ S D ~}$ & $\begin{array}{c}\% \\
\text { Nominal }\end{array}$ & $\begin{array}{c}\% \\
\text { RSD }\end{array}$ & SEM \\
\hline 1 & 10 & 10.07 & 0.316 & 100.72 & 3.136 & 0.182 \\
2 & 10 & 10.12 & 0.154 & 101.24 & 1.523 & 0.089 \\
3 & 10 & 10.07 & 0.275 & 100.66 & 2.735 & 0.159 \\
1 & 100 & 99.24 & 1.475 & 99.24 & 1.487 & 0.852 \\
2 & 100 & 100.86 & 1.326 & 100.86 & 1.315 & 0.766 \\
3 & 100 & 99.52 & 0.869 & 99.52 & 0.873 & 0.501 \\
1 & 200 & 200.7 & 0.945 & 100.35 & 0.471 & 0.545 \\
2 & 200 & 200.71 & 0.741 & 100.36 & 0.369 & 0.428 \\
3 & 200 & 203.27 & 0.71 & 101.64 & 0.349 & 0.41 \\
1 & 300 & 301.06 & 1.071 & 100.35 & 0.356 & 0.618 \\
2 & 300 & 307.48 & 3.16 & 102.49 & 1.028 & 1.824 \\
3 & 300 & 304.11 & 2.103 & 101.37 & 0.692 & 1.214 \\
\hline
\end{tabular}

SEM = standard error of the mean; 1, 2 and 3 represents measurements obtained on day 1 , day 2 and day 3 , respectively ( $n=3$ for each day)

Table 3: Intra- and inter-day precision for assay of CRZ by the proposed spectrofluorimetric method

\begin{tabular}{|c|c|c|c|c|}
\hline \multirow{2}{*}{$\begin{array}{l}\text { Nominal } \\
\text { conc. } \\
\text { (ng/mL) }\end{array}$} & \multicolumn{2}{|c|}{ Intra-day } & \multicolumn{2}{|c|}{ Inter-day } \\
\hline & $\begin{array}{l}\text { Measured conc. } \\
(\mathrm{ng} / \mathrm{mL})\end{array}$ & $\begin{array}{c}\text { Recovery }(\% \pm \\
\text { RSD) }\end{array}$ & $\begin{array}{c}\text { Measured conc. } \\
(n g / m L)\end{array}$ & $\begin{array}{c}\text { Recovery }(\%, \pm \\
\text { RSD) }\end{array}$ \\
\hline 10 & 10.07 & $100.87 \pm 0.316$ & 10.07 & $99.50 \pm 1.475$ \\
\hline 100 & 99.24 & $99.87 \pm 0.869$ & 99.52 & $99.03 \pm 1.326$ \\
\hline 200 & 200.7 & $100.78 \pm 0.741$ & 203.27 & $100.67 \pm 0.819$ \\
\hline 300 & 301.06 & $100.41 \pm 1.071$ & 304.11 & $100.36 \pm 1.68$ \\
\hline
\end{tabular}

${ }^{\mathrm{a}}$ Mean of three determinations 
Table 4: Robustness of the proposed spectrofluorimetric method

\begin{tabular}{|c|c|}
\hline Parameter variation & Recovery $\left(\%, \pm \mathrm{SD}^{\mathrm{a}}\right.$ \\
\hline No variation ${ }^{\mathrm{b}}$ & $99.68 \pm 0.88$ \\
\hline \multicolumn{2}{|l|}{ SDS volume $(\mu \mathrm{L})$} \\
\hline 180 & $100.02 \pm 2.223$ \\
\hline 220 & $102.79 \pm 0.545$ \\
\hline \multicolumn{2}{|l|}{ Acid concentration $(\mathrm{N})$} \\
\hline 0.8 & $101.31 \pm 1.306$ \\
\hline 1.2 & $104.25 \pm 0.631$ \\
\hline \multicolumn{2}{|l|}{ Acid volume $(\mu \mathrm{L})$} \\
\hline 0.95 & $100.07 \pm 0.545$ \\
\hline 1.05 & $104.25 \pm 0.452$ \\
\hline \multicolumn{2}{|l|}{ Temperature $\left(\mathrm{C}^{\circ}\right)$} \\
\hline 20 & $103.33 \pm 0.770$ \\
\hline 30 & $098.25 \pm 0.981$ \\
\hline
\end{tabular}

Table 5: Assay results for CZB in pure form and human plasma samples

\begin{tabular}{cccc}
\hline \multicolumn{1}{c}{ Pure form } & Plasma \\
\hline $\begin{array}{c}\text { Amount } \\
\text { taken } \\
(\mathbf{n g} / \mathbf{m L})\end{array}$ & \% Found & $\begin{array}{c}\text { Amount } \\
\text { taken } \\
(\mathbf{n g} / \mathbf{m L})\end{array}$ & \% Found \\
\hline 40 & 100.83 & 150 & 99.9 \\
100 & 100.26 & 200 & 99.98 \\
300 & 100.95 & 250 & 0.2 \\
\hline Mean & 100.68 & & 99.98 \\
\pm S.D. & 0.367 & & 0.199 \\
\hline
\end{tabular}

\section{Application to CRZ in human plasma}

The suggested spectrofluorimetric procedure was applied for assaying CRZ in plasma samples. The maximum plasma concentration of CRZ is reached after oral administration of a single CRZ dose of $250 \mathrm{mg}$ by $4 \mathrm{~h}$ [22]. The $\mathrm{C}_{\max }$ of CRZ is reported to be $274 \mathrm{ng} / \mathrm{mL}$ [20]. Accordingly, CRZ could be assayed efficiently by the adopted method as the $\mathrm{C}_{\max }$ lied in our dynamic range (Table 1). Mean of the relative recoveries and \% RSD of CRZ in plasma samples are presented in Table 5 (99.98 and $0.199 \%$, respectively).

\section{DISCUSSION}

Fluorescence spectrum of any molecule depends on absorbing of electromagnetic radiation by the molecule. On examining the fluorescence behavior of $C R Z$, it was found that $C R Z$ exhibited two peaks. The first one represented the excitation band with maximum intensity at 271 $\mathrm{nm}$ while the other one represented the emission band with maximum intensity at $404 \mathrm{~nm}$.

This indicated the intrinsic fluorescence property of CRZ. As a trial to increase the FI of CRZ and hence the sensitivity of the proposed method, different surfactants were added to CRZ solution. It was found that addition of SDS, an anionic surfactant, led to increment of CRZ fluorescence intensity by enhancement of its absorption at 271 $\mathrm{nm}$ (excitation wavelength). This was confirmed by calculation of the molar absorptivity of $C R Z$ in SDS $\left(\varepsilon_{\text {micellar }}\right)$ and that of $\mathrm{CRZ}$ in $\mathrm{HCl}$ solution $\left(\varepsilon_{\mathrm{HCI}}\right)$ at $271 \mathrm{~nm}$. The value of $\varepsilon_{\text {micellar }}$ was $5.085 \times 105$ while that of $\varepsilon_{\mathrm{HCl}}$ was $3.3 \times 10^{5}$. Upon calculation of quantum yield of CRZ in SDS and $\mathrm{HCl}$ respectively, it was noticed that there is no difference between the two values at $271 \mathrm{~nm}$ indicating that the enhanced effect of SDS was due to increasing CRZ molar absorptivity only.

The quantum yield of CRZ in SDS medium was calculated Eq 3 [15]:

$\emptyset c=\varnothing q(F c / F q \times A q / A c)$

where $\emptyset c$ and $\emptyset q$ are the quantum yields of CRZ in SDS medium and quinine, respectively. Fc and $\mathrm{Fq}$ are the integral fluorescence intensities of the $\mathrm{CRZ}$ and quinine, respectively; Ad and Aq are the absorbance values of $\mathrm{CRZ}$ and quinine at excitation wavelength, respectively. In order to reduce the error of the inner effect, we selected concentration of CRZ of absorbance value $<0.05$ [23].

\section{CONCLUSION}

The current work is the first spectrofluorimetric approach, to the best of our knowledge, for the assay of CRZ in spiked human plasma samples as well as bulk powder form. The adopted method, based on measuring native fluorescence of the cited drug, is sensitive and simple and gave reproducible results for $C R Z$ determination in very low concentration levels.

Another advantage is the green nature of the method because no organic solvent was used except during extraction of CRZ from plasma matrix. Thus, the developed procedure can be used in clinical and quality control laboratories.

\section{DECLARATIONS}

\section{Acknowledgement}

The authors would like to extend their sincere appreciation to Deanship of Scientific Research at King Saud University for funding this work through Research Group Project no. RGP-322. 


\section{Conflict of Interest}

No conflict of interest associated with this work.

\section{Contribution of Authors}

The authors declare that this work was done by the authors named in this article and all liabilities pertaining to claims relating to the content of this article will be borne by them.

\section{REFERENCES}

1. Ou S. Crizotinib: a novel and first-in-class multitargeted tyrosine kinase inhibitor for the treatment of anaplastic lymphoma kinase rearranged non-small cell lung cancer and beyond. Drug Des Devel Ther 2011; 5(5): 471-485.

2. Rodig SJ, Shapiro GI. Crizotinib, a small-molecule dual inhibitor of the c-Met and ALK receptor tyrosine kinases. Curr Opin Investig Drugs (London, England: 2000) 2010; 11(12): 1477-1490.

3. Kwak EL, Bang Y-J, Camidge DR, Shaw AT, Solomon B, Maki RG, Ou S-HI, Dezube BJ, Jänne PA, Costa DB. Anaplastic lymphoma kinase inhibition in non-small-cell lung cancer. N Engl J Med 2010; 363(18): 1693-1703.

4. Cui JJ, Tran-Dubé M, Shen H, Nambu M, Kung P-P, Pairish M, Jia L, Meng J, Funk L, Botrous I. Structure based drug design of crizotinib (PF-02341066), a potent and selective dual inhibitor of mesenchymal-epithelial transition factor (C-MET) kinase and anaplastic lymphoma kinase (ALK). J Med Chem 2011; 54(18): 6342-6363.

5. Kazandjian D, Blumenthal GM, Chen H-Y, He K, Patel M, Justice $R$, Keegan P, Pazdur R. FDA approval summary: crizotinib for the treatment of metastatic nonsmall cell lung cancer with anaplastic lymphoma kinase rearrangements. Oncologist 2014; 19(10): e5-e11.

6. Huang X, Cai J, Wang X. LC-MS Determination of Crizotinib in Rat Plasma and its Application to a Pharmacokinetic Study. Lat Am J Pharm 2014; 33: 1188-1192.

7. Roberts MS, Turner DC, Broniscer A, Stewart CF. Determination of crizotinib in human and mouse plasma by liquid chromatography electrospray ionizationtandem mass spectrometry (LC-ESI-MS/MS). J Chromatogr B 2014; 960: 151-157.

8. Sparidans RW, Tang SC, Nguyen LN, Schinkel AH, Schellens JH, Beijnen JH. Liquid chromatographytandem mass spectrometric assay for the ALK inhibitor crizotinib in mouse plasma. J Chromatogr B 2012; 905. 150-154.

9. Wani $T$, lqbal $M$, Darwish I, Khalil N, Zargar $S$. Development and validation of sensitive uplc- $m s / m s$ based method for the estimation of crizotinib in human plasma. Dig J Nanomater Biostruct 2014; 9(2): 693-704.
10. Khalil NY, Wani TA, Darwish IA, Al-Majed A-RA. Highly sensitive hplc method with non-extractive sample preparation and fluorescence detection for determination of crizotinib in human plasma. Lat Am J Pharm 2014; 33(6): 1019-1026.

11. Darwish IA, Alshehri JM, Alzoman NZ, Khalil NY, AbdelRahman HM. Charge-transfer reaction of 1, 4benzoquinone with crizotinib: Spectrophotometric study, computational molecular modeling and use in development of microwell assay for crizotinib. Spectrochim Acta A Mol Biomol Spectrosc. 2014; 131: 347-354.

12. Wani TA, Darwish IA. A novel 96-microwell-based highthroughput spectrophotometric assay for pharmaceutical quality control of crizotinib, a novel potent drug for the treatment of non-small cell lung cancer. Braz J Pharm Sci. 2015; 51(2): 439-447.

13. Darwish IA, Alshehri JM, Alzoman NZ, Khalil NY, AbdelRahman HM. Charge-transfer reaction of chloranilic acid with crizotinib: Spectrophotometric study, computational modeling and use in development of microwell assay for crizotinib. J Solution Chem. 2014; 43(7): 1282-1295.

14. Kaur K, Saini SS, Malik AK, Singh B. Micelle enhanced and terbium sensitized spectrofluorimetric determination of danofloxacin in milk using molecularly imprinted solid phase extraction. Spectrochim Acta A Mol Biomol Spectrosc.2012; 96: 790-795.

15. Tang B, Wang $X$, Jia B, Niu J, Wei $Y$, Chen Z, Wang $Y$. Simple, rapid, and sensitive spectrofluorimetric determination of Zaleplon in micellar medium. Anal. Lett. 2003; 36(14): 2985-2997.

16. Wang CC, Masi AN, Fernández L. On-line micellarenhanced spectrofluorimetric determination of rhodamine dye in cosmetics. Talanta 2008; 75(1): 135140.

17. $h$ ttp://www.chemicalize.org/structure/\#!mol=crizotinib\&so urce=fp. $(2016,28-3-2016)$.

18. Miller JN, Miller JC. Statistics and chemometrics for analytical chemistry: Pearson Education; 2005.

19. Huber L. Validation and qualification in analytical laboratories, Informa Healthcare USA. Inc: New York 2007: 125-155.

20. U.S. Food and Drug Administration (FDA). Crizotinib pdiatric ODAC meeting MD, USA: Center for drug evaluation and Research,; November 2010.

21. ICH. Validation of Analytical procedures. Methodology (Q2AR1), International Conference on Harmonization; November 1996 and November 2005; USA:: Food and Drug Administration; November 1996 and November 2005.

22. Li C, Alvey C, Bello $A$, Wilner $K$, Tan $W$. Pharmacokinetics (PK) of crizotinib (PF-02341066) in patients with advanced non-small cell lung cancer (NSCLC) and other solid tumors. ASCO Annual Meeting Proceedings; 2011; 2011. p. e13065.

23. Lakowicz JR. Principles of fluorescence spectroscopy: Springer Science \& Business Media; 2007. 